\title{
Clinical Trial Investigator Site Documentation
}

National Cancer Institute

\section{Source}

National Cancer Institute. Clinical Trial Investigator Site Documentation. NCI Thesaurus.

Code C115654.

Records pertaining to an investig ator site in a clinical trial. 